\title{
GRADUATE BUSINESS STATISTICS: COMPARSION OF GRADES FROM ONLINE AND ON- GROUND COURSES
}

Jong-Sung Lee, Middle Tennessee State University, Murfreesboro, TN

Gordon L. Freeman, Jr., Middle Tennessee State University, Murfreesboro, TN

dx.doi.org/10.18374/JIMS-14-1.14

\begin{abstract}
The explosive growth of online education seems to slow down. Does this trend indicate that some courses are not appropriate for online education? We sought to find an answer to this question regarding graduate business statistics. We assumed that a course is well suited for online education if the students in the online and on-ground courses make overall grades that are not significantly different. We found that overall grades in the online graduate business statistics course were not significantly different from those in the on-ground course, though there was significant difference between the midterm grades of the two versions of courses. We assumed that it was due to the difference of learning speed. Comparison of letter grade distributions of the two modes of learning led us to the same conclusion. The results of this study led us to believe that graduate business statistics is appropriate for online education. We also recommend further research on students' perceptions on the two learning environments to find how to reduce or remove the difference in learning speed.
\end{abstract}

Keywords: Online Course, Graduate Business Statistics 